\title{
Calibration of the X-ray Diffraction Technique in Measuring In-service Stresses in Corrugated Steel Bars
}

\author{
Santiago Sánchez-Beitia ${ }^{1} \cdot$ Daniel Luengas-Carreño ${ }^{1}\left[\right.$ · Paulo B. Lourenço ${ }^{2}(0$
}

Received: 4 September 2020 / Accepted: 8 October 2021 / Published online: 25 October 2021

(c) The Author(s) 2021

\begin{abstract}
The X-ray diffraction technique for determining residual stresses in construction steels has been commonly used in the international scientific community for decades. Taking advantage of the concepts on which the technique is based, the authors have previously calibrated and used the technique for the in situ determination of the stress states of metallic structures in service. This article presents an advance in the latter utility by means of the laboratory calibration of the X-ray diffraction technique in corrugated steel. The interaction between radiation and steel is complex, so, in the scientific community, it is considered pertinent to resort to empirical and experimental calibration processes. Two bars of corrugated steel were subjected to increasing tensile loads. The load states introduced in the testing machine were compared with those determined by $\mathrm{X}$-ray diffraction. The correlation between the values of the loads applied and those determined by the proposed technique is excellent. The experimental conditions of the calibration tests are precisely detailed so that they are easily reproducible. This work represents a necessary first step in employing the technique in the buildings or civil works.
\end{abstract}

Keywords Corrugated steel $\cdot$ X-ray diffraction $\cdot$ State of stress $\cdot$ Non-destructive testing

\section{Introduction}

Since its commercialization at the end of the 1970s, specific laboratory equipment that uses the X-ray diffraction technique to quantify residual stresses has been widely used in the scientific community. In the 1980s, many scientific contributions were presented in this field of research (Atienza et al., 2006, 2012; Beck et al., 1989; Elices et al., 1983; FIP-78, 1978; Fujiwara et al., 1992; He et al., 2003; Macherauch et al., 1987; Willemse et al., 1982) for the aeronautics, automotive, railroad and construction (prestressed steel) sectors. The ASTM, originally known as American Society for Testing and Materials, has published several updates to the standard for the quantification of residual stresses by X-ray diffraction (ASTM E2860-12, 2012; ASTM E142614, 2014; ASTM E915-16, 2016). This type of stress, which

Daniel Luengas-Carreño

daniel.luengas@ehu.eus

1 High Technical School of Architecture, University of the Basque Country UPV/EHU, Plaza Oñati 2, 20018 Donostia-San Sebastián, Spain

2 Department of Civil Engineering, ISISE, University of Minho, 4800-058 Guimarães, Portugal naturally originates in the processes of preparing and shaping any metallic element, was initially considered harmful or anomalous because it altered the state of the stress of a structure in service. The manufacturing processes of steel were developed so that a high level of compressive stresses was intentionally applied to inhibit the appearance of surface cracks. These processes, such as shot peening, protect metallic components against the phenomena of fatigue, corrosion under stress and corrosion fatigue (Artaraz \& SánchezBeitia, 1991; McClung, 2007; Noyan \& Cohen, 1987; Ruiz et al., 2003).

In cases in which it is necessary to know the stress state of a structure in service, it is necessary to develop nondestructive techniques and methods that are applicable in situ. An added problem is that it is, usually, not possible to load or unload the structure to perform comparative measurements. In the international scientific community, it is assumed that X-ray diffraction can resolve this problem in metallic components.

This article presents the first phase for the use of the X-ray diffraction technique in reinforced concrete structures. Two corrugated steel bars with diameters of $20 \mathrm{~mm}$ were tested in the laboratory. The steel type is ferritic-pearlitic of B400S quality according to the standard UNE 36068 (2011), with 
a conventional shape (ribbed bar) provided by the manufacturer and without any treatment prior to the tests. Initially, the residual stresses on the unloaded bars were quantified. Subsequently, they were subjected to various known load stress levels, and the stress state was quantified by diffraction in each load state. The tests were performed in the laboratories of the School of Civil Engineering of University of Minho, in Guimarães (Portugal). The X-ray diffraction equipment available for in situ work was moved from the laboratories of the two first authors.

\section{Formulation and Concepts of the X-ray Diffraction Technique}

This technique is based on the detection of the separation "d" of the crystallographic planes of the crystallization phases as a function of the stress value. In the case of steels, these phases can be ferrite, austenite or martensite. The separation of the crystallographic planes can be considered the strain gage of the technique (Bhadeshia, 2002; Castex et al., 1981; Hilley, 1971; Withers \& Bhadeshia, 2001a, 2001b). The phenomenon of X-ray diffraction is a "reflection" of incident radiation on crystallographic planes that occurs only for a given angle of incidence. They must be understood under the postulates of quantum mechanics and as being different from a conventional reflection, which occurs for any angle of incidence. The relationship between the angle of the diffracted radiation and the separation of the crystallographic planes of the sample is defined by the Bragg diffraction law:

$2 d_{0} \sin \theta_{0}=n \lambda$

where $\mathrm{n}$ is the diffraction order, $\lambda$ is the wavelength of the radiation and $\mathrm{d}_{0}$ and $\theta_{0}$ are the separation of the crystallographic planes and the diffraction angle in the samples not subjected to loading, respectively (Fig. 1). No diffracted radiation was detected in any direction other than $\theta_{0}$.

Steel can be defined as a polycrystalline and polyphasic material consisting of a solid carbon solution in a crystalline iron lattice. The steel is solidified in cells called grains with variable diameters (usually between 5 and 20 microns). Each grain is a monocrystal with its crystallographic planes of interest oriented randomly with respect to the adjacent grains. Only a small portion of the grains affected by the radiation contribute to the generation of the diffraction phenomenon. Figures 2 and 3 show two diagrams of the diffraction phenomenon in a single-phase steel.

A stress state is manifested by a new value of the separation of the crystallographic planes " $\mathrm{d}_{\varphi \psi}$ " with respect to the value in the unloaded situation " $\mathrm{d}_{0}$ " and consequently a variation of the diffraction angle " $\theta_{\varphi \psi}$ " with respect to " $\theta_{0}$ ", according to Bragg's law. The $\varphi$ and $\psi$ angles define the

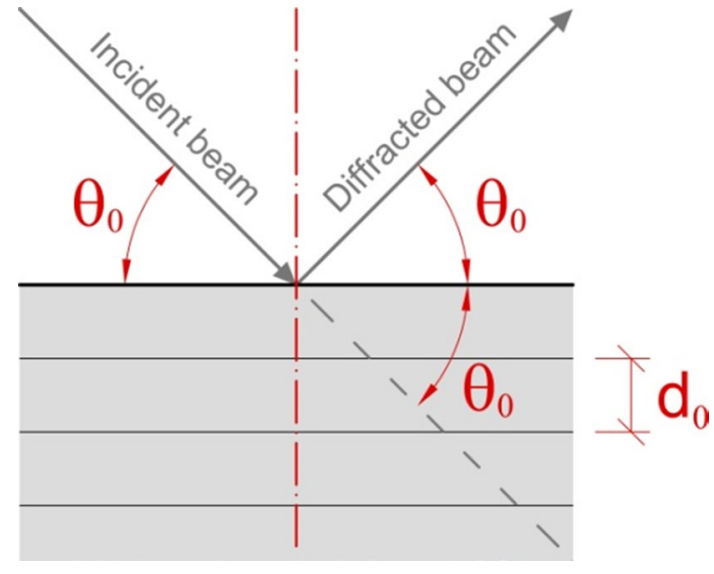

Fig. 1 Diagram of the diffraction phenomenon

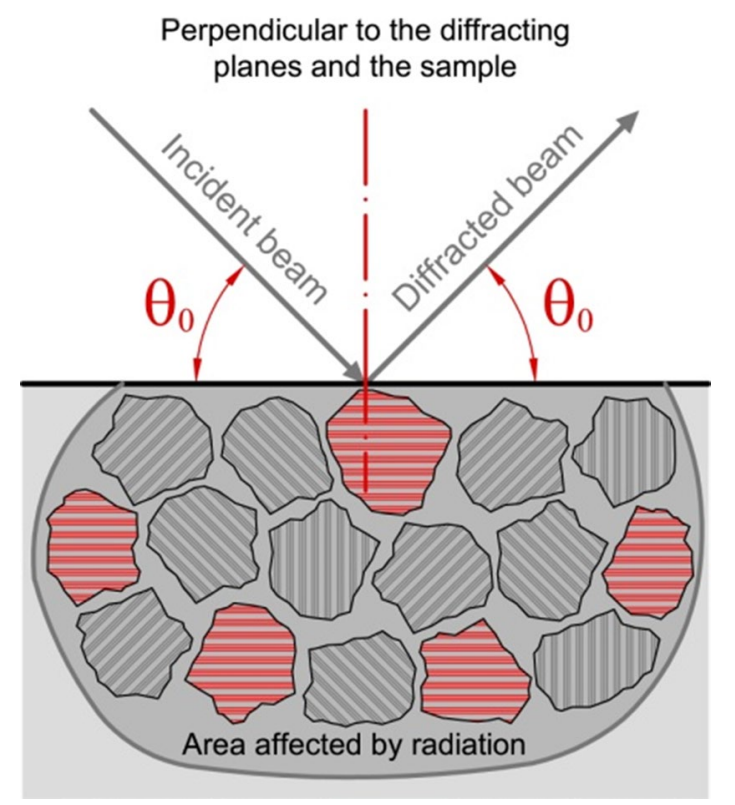

Fig. 2 Diagram of the diffraction phenomenon on the grains with their crystallographic planes of interest (marked in red) parallel to the surface of the sample. (Color figure online)

spatial arrangement perpendicular to the crystalline planes that contributes to diffraction (Figs. 3 and 4 ) in the main reference system $\left(\left\{X_{1} X_{2} X_{3}\right\}\right)$.

Differentiating by Bragg's law, the following relationship is obtained:

$\frac{d_{\varphi \psi}-d_{0}}{d_{0}} \approx-\cot \theta_{0}\left(\theta_{\varphi \psi}-\theta_{0}\right)$

The diffraction technique identifies the deformation $\varepsilon_{\varphi \psi}$ in the direction defined by the angles $\varphi$ and $\psi$ with the first term of the previous expression. Given that steel is a 


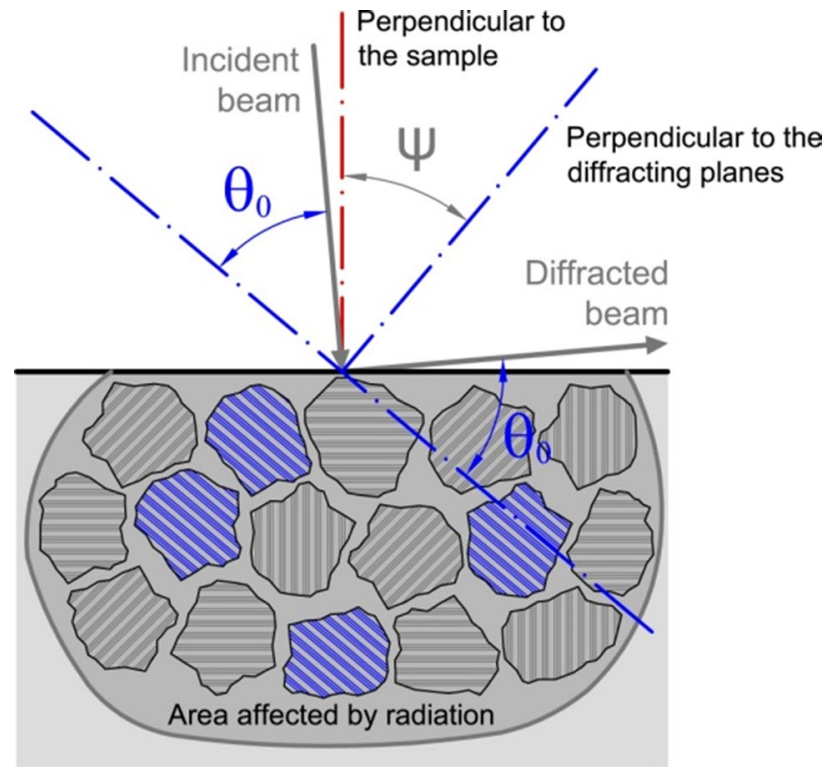

Fig. 3 Diagram of the diffraction phenomenon on the grains with their crystallographic planes of interest (marked in blue) not parallel to the surface of the sample, which contributes to diffraction. (Color figure online)

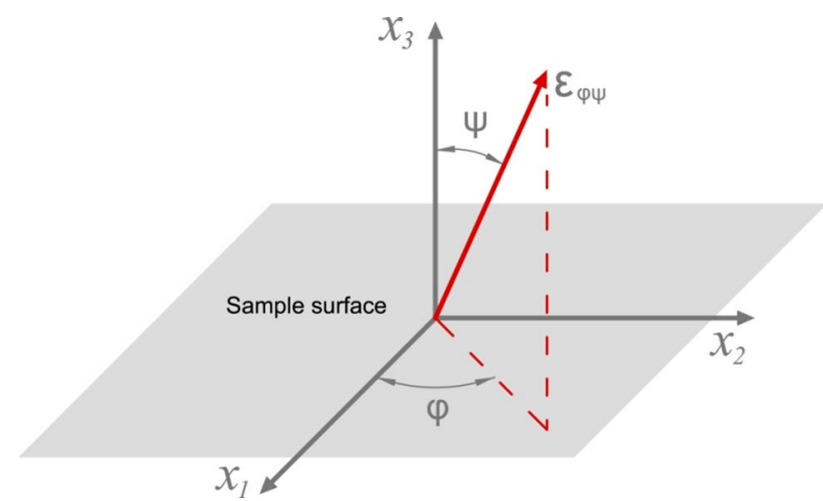

Fig. $4\left\{X_{1} X_{2} X_{3}\right\}$ represents the principal state of the stress system, while the direction of $\varepsilon_{\varphi \psi}$ is coincident with the direction perpendicular to the plane diffraction

continuous, homogeneous and isotropic material (in most situations except for very specific cases of steels with a crystallographic texture) and that the stress gradient is reduced in the area affected by radiation (a surface circle with a diameter of $2 \mathrm{~mm}$ and a depth of $0.1 \mathrm{~mm}$ ), Hooke's law can be used to deduce the following expression:

$\varepsilon_{\varphi \psi}=\frac{1+v}{E} \sigma_{\varphi} \sin ^{2} \psi-\frac{\nu}{E}\left(\sigma_{11}-\sigma_{22}\right)$

where $v$ is the Poisson coefficient, E is Young's Modulus for steel, $\sigma_{\varphi}$ the stress in the direction defined by the angles $\varphi$ and $\psi=\pi / 2$, and the terms $\sigma_{11}$ and $\sigma_{22}$ are the principal stresses. The term $\sigma_{\varphi}$ is expressed as follows: $\sigma_{\varphi}=\sigma_{11} \cos ^{2} \varphi+\sigma_{22} \cos ^{2} \varphi$

The slope of the line of $\varepsilon_{\varphi \psi}$ vs. $\sin ^{2} \psi$ (Eq. 3) allows the stress $\sigma_{\varphi}$ to be obtained on the surface of the sample, known as its elastic constants. The above expressions can be reformulated as follows:

$\theta_{\varphi \psi}=\theta_{0}+1 / 2 C_{1} \sigma_{\varphi} \sin ^{2} \psi+1 / 2 C_{2}\left(\sigma_{11}+\sigma_{22}\right)$

where

$C_{1}=\frac{1+v}{E} \tan \theta_{0}$

$C_{2}=\frac{v}{E} \tan \theta_{0}$

Expressions (3) and (5) are two versions of the " $\sin ^{2}$ law". In areas close to the surface, the stress state can be considered to be a plane stress state $\left(\sigma_{33}=0\right)$. In standard X-ray diffraction equipment for the quantification of stresses, $\theta_{\varphi \psi}$ values are recorded for various inclinations $\psi$ (goniometer scan) for a predetermined value of the angle $\varphi$ (Fig. 5). The software of these devices obtains a value of $\sigma_{\varphi}$ through a least squares adjustment.

$\mathrm{X}$-ray diffraction is sensitive to the parameter that identifies the stress state, which in the present case is the variation of the distance "d" between the crystallographic planes of the material. The $\mathrm{X}$ - rays do not make a distinction between the residual stresses and the stresses resulting from the

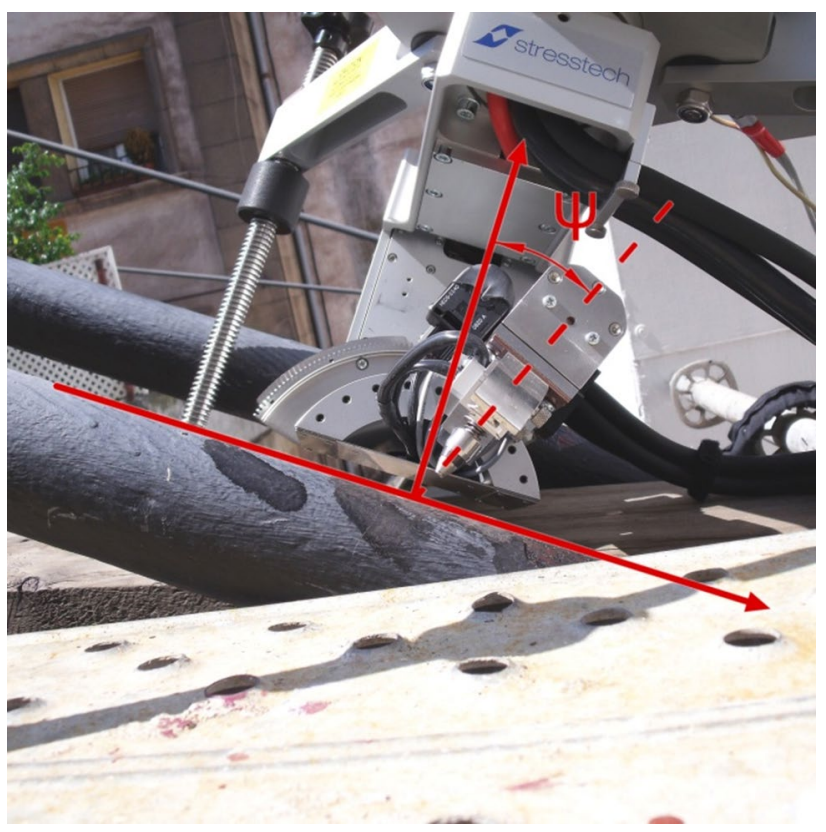

Fig. 5 Position of the X-ray emitter in the goniometer scanning process (circular element in the image). Its inclined position is observed perpendicular to the bar 
applied loading (Sánchez-Beitia, 2011). In the latter case, the stresses determined by X-ray diffraction will be the sum of the residual stresses and those applied to the structure (i.e. in service). Both values can be obtained by appropriate tests as explained below. The residual stresses are obtained by applying the technique to elements that are not subjected to external loads, either a sample of the material extracted from site or a sample of the material available in the market. The actual stresses in service can be determined by applying the in situ technique. Once the total stresses are known, it is possible to obtain the structural stresses by subtracting the residual stresses from the total stresses (Sánchez-Beitia $\&$ Barrallo, 2014). Figure 6 shows a diagram of both stress states.

This process has been used by the authors to quantify prestressed steel structures and metal bar structures. First, the laboratory calibration of the X-ray diffraction technique was performed on smooth bars and wires (Sánchez-Beitia, 1988, 2011). Subsequently, the stress states in the Bizkaia Bridge, a World Heritage Site, were determined (Sánchez-Beitia \& Barrallo, 2014). The scientific equipment used is the same in both cases under two arrangements: laboratory (Fig. 7) and in situ work (Fig. 8). In the first case, the equipment allows programmed variations of the angles $\varphi$ and $\psi$, while in the in situ disposition, it only makes automated turns in $\psi$ (the $\varphi$ variations must be done manually).

The interaction between radiation and steel that determines the stress states is complex due to several factors. If the crystallographic planes are identified by their Miller indices $\{\mathrm{hkl}\}$, the elastic constants will be linked to them

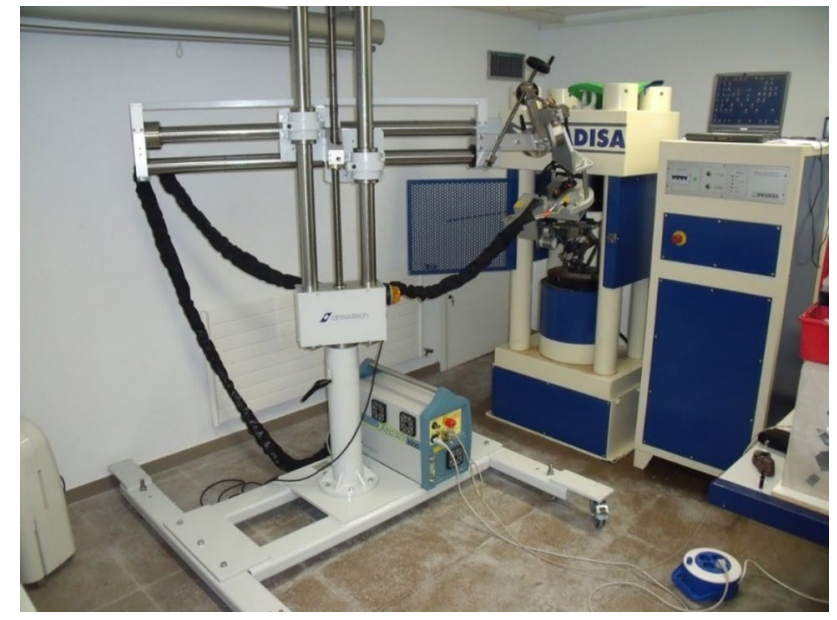

Fig. 7 Arrangement of the equipment in the laboratory

by defining the constants defined as $v\{h k l\}$ and $\mathrm{E}\{\mathrm{hkl}\}$. On the other hand, as already mentioned, only a small part of the volume of a material affected by radiation contributes to diffraction. This situation suggests that the determined stress states are those of that small proportion, not of the material as a whole. Both questions can be solved by complex experimental and mathematical processes (Barral, 1983; Hilley, 1971; Kröner, 1958; Reuss, 1929; Sánchez-Beitia, 1990; Sprauel, 1988; Voigt, 1910). However, an alternative solution for obtaining the stress states with excellent results is to perform empirical experimental processes. This is the calibration process performed in this article.
Fig. 6 Schematic diagram of the residual and structural stress values (left) and the sum of both states (right) as a function of sample depth. The area affected by the residual stresses is approximately $0.5 \mathrm{~mm}$
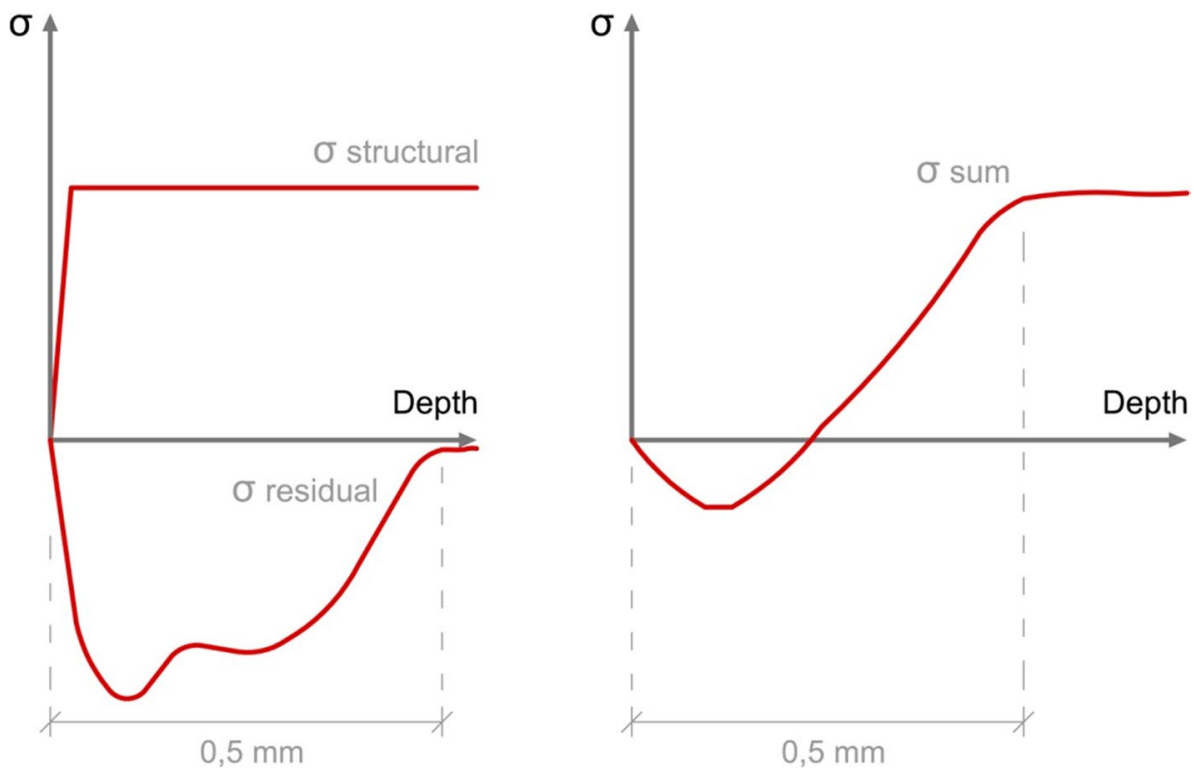


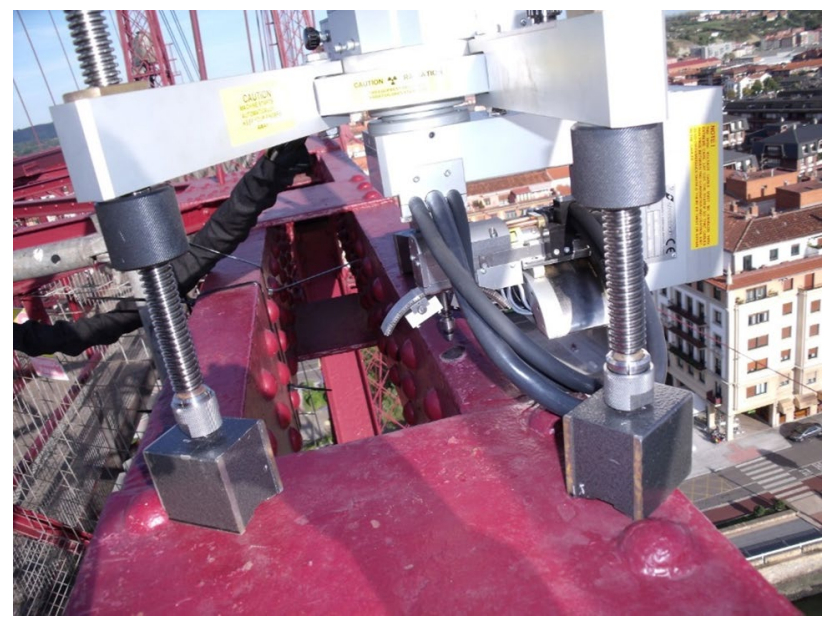

Fig. 8 Portable arrangement of the equipment on the Bizkaia Bridge at a height of $60 \mathrm{~m}$

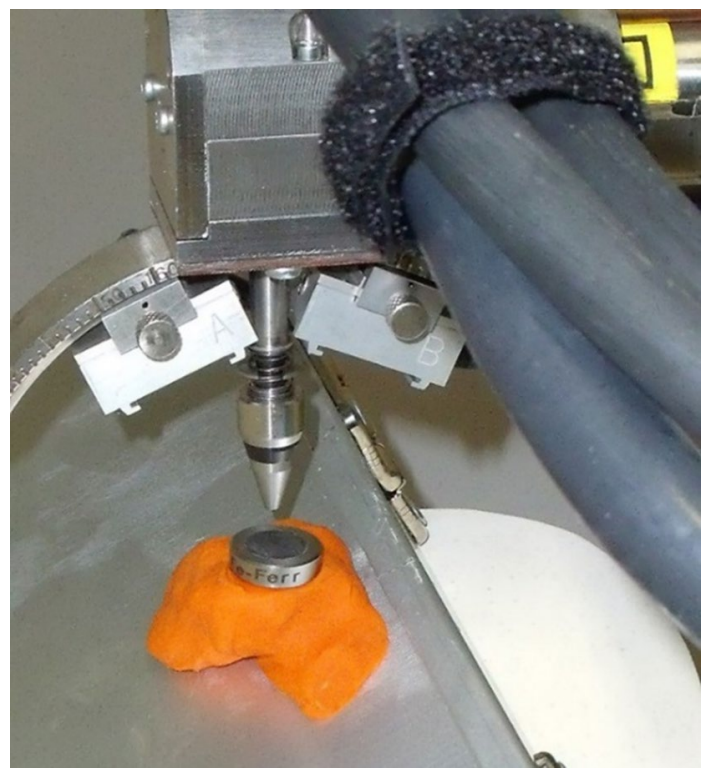

Fig. 9 Detail of the calibration process on a powder sample. The "A" and " $\mathrm{B}$ " radiation detectors identify the angle of the diffracted radiation $\left(2 \theta_{0}\right)$

\section{Tests and Results}

\subsection{Taring Process of the Equipment}

The equipment used in the tests was previously tared on a powder sample (Fig. 9) with a stress state of zero. The sample was supplied by the manufacturer of the diffraction equipment and consisted of a compacted ferritic steel powder $\left(\mathrm{E}=211,000 \mathrm{MPa}, v=0.3\right.$ and $\left.2 \theta_{0}=156.45^{\circ}\right)$. This process allowed us to define some basic conditions of the diffraction process that were used in all subsequent tests and ensure that the equipment was in perfect condition. In this type of steel, the crystallographic planes of interest are defined by Miller indices $\{211\}$ that generate the first order of diffraction $(n=1)$, in the Bragg diffraction law. The equipment makes successive measurements automatically while varying the geometric parameters of diffraction until the stress value is the "best" possible.

The radiation is defined as $\mathrm{CrK} \alpha$ (wavelength: $\lambda=0.2291 \mathrm{~nm}$ ) with an excitation voltage of 29.4 kilovolts and an intensity of 3.06 milliamps. The distance from the source of the radiation to the powder sample was $14.54 \mathrm{~mm}$. The number of inclinations of the sweep " $\psi$ " over which the " $\sin ^{2}$ law" was applied was nine (four in positive inclinations and four in negative inclinations plus the vertical position), and diffracted radiation was collected for $5 \mathrm{~s}$ in each inclination. The diffraction peaks generated during this period of time presented a "full width at half maximum" (FWHM) of $3.105 \pm 0.061$ degrees of the angle $\theta_{\varphi \psi}$ in all cases. This parameter indicates the quality of the diffracted radiation; the lower its value is, the lower the margin of error of the diffraction angle values $(\Delta 2 \theta)$ is, and therefore, the lower the error are in the obtained stresses. Its value depends on the number of grains diffracting and the vibration in the working environment. The conditions of the diffraction process that "best" approach a zero value of stress $\left(\sigma_{\varphi}\right)$ for an angle $2 \theta_{0}=156.45^{\circ}$ are shown in Table 1 . "the lower the error are in the obtained stresses" and "the number of grains diffracting".

\subsection{Determination of Residual Stresses}

The second experimental step consisted of quantifying the residual stresses on two corrugated steel bars (Figs. 10 and

Table 1 Values of the diffraction conditions on a powder sample

\begin{tabular}{llllllll}
\hline Radiation & Voltage $(\mathrm{kV})$ & Intensity $(\mathrm{mA})$ & “D” $(1)$ & Angles $\psi(2)$ & “T”(3) & Stress state $(\mathrm{MPa})$ & FWHM $\left({ }^{0}\right)$ \\
\hline $\mathrm{CrK} \alpha$ & 24.9 & 3.06 & 14.54 & $0,+/-18.7,+/-27,+/-33.8,+/-40$ & 5 & $2.2+/-8,8$ & $3.105+/-0.061$ \\
\hline
\end{tabular}

The programmed and determined parameters are indicated in the first row

(1) Distance from the X-ray emitter to the sample (mm). (2) Scanning angles $\psi\left({ }^{\circ}\right)$. (3) Radiation time at each inclination $\psi(\mathrm{s})$ 


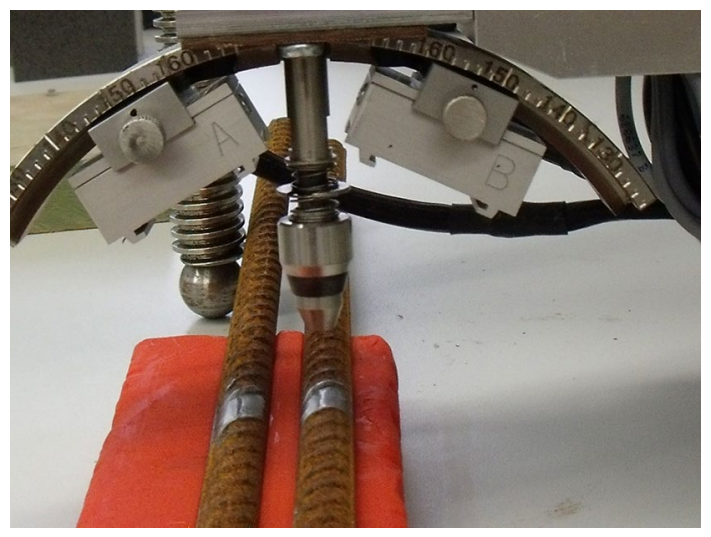

Fig. 10 Detail of the quantification process of the residual stresses in one of the analyzed bars. The sweep $\psi$ of the goniometer is perpendicular to the plane of the figure

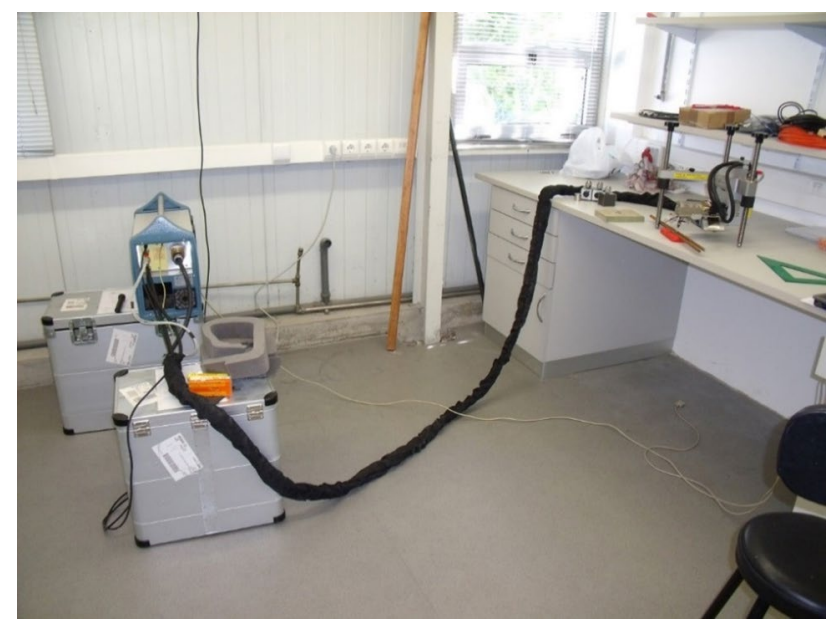

Fig. 11 Overview of the process of determining the residual stresses

11) that were subsequently loaded in tension. Previously, the area affected by radiation was cleaned by a light electrolytic polish, a technique that does not introduce external stresses.

The quantification process of the residual stresses was repeated several times by changing the position of the bars on the laboratory bench and starting the equipment in each case. The corrugated steels have a ferritic-pearlitic microstructure in which only the ferritic phase contributes to the diffraction. The general characteristics of the analyzed steel correspond to the B400S quality according to Norms UNE 36068 (2011) and UNE 36065 (2011). The modulus of elasticity and the Poisson coefficient are 210,000 MPa and 0.28, respectively.

The value of the residual stress in all cases is approximately $280 \mathrm{MPa}$ in compression (values with negative signs $)$ in the direction of the bars $(\varphi=0$ in Tables 2,3 and 4 ) with very low scatter. The equipment returns values for
Table 2 Experimental data of the quantification of the residual stresses in Bar 1

\begin{tabular}{llll}
\hline Angle $\psi\left({ }^{\circ}\right)$ & $\mathrm{d}_{\varphi \psi}(\mathrm{nm})$ & FWHM $\left(^{0}\right)$ & Residual stresses $\sigma^{\text {rs1 }}(\mathrm{MPa})$ \\
\hline Bar 1 & & & \\
0 & 0.117127 & 3.12 & \\
-18.7 & 0.117101 & 3.21 & \\
-27 & 0.117079 & 3.35 & \\
-33.8 & 0.117054 & 3.49 & $-280.9 \pm 14.7$ \\
-40 & 0.117038 & 3.69 & \\
18.7 & 0.117116 & 3.16 & \\
27 & 0.117099 & 3.22 & \\
33.8 & 0.117079 & 3.30 & \\
40 & 0.117058 & 3.40 & \\
\hline
\end{tabular}

Table 3 Experimental data of the quantification of the residual stresses in Bar 2

\begin{tabular}{llll}
\hline Angle $\psi\left({ }^{\circ}\right)$ & $\mathrm{d}_{\varphi \psi}(\mathrm{nm})$ & FWHM $\left(^{0}\right)$ & Residual stresses $\sigma^{\mathrm{rs} 2}(\mathrm{MPa})$ \\
\hline Bar 2 & & & \\
0 & 0.117130 & 3.03 & \\
-18.7 & 0.117102 & 3.18 & \\
-27 & 0.117081 & 3.30 & \\
-33.8 & 0.117051 & 3.52 & $-279.7 \pm 20.4$ \\
-40 & 0.117037 & 3.73 & \\
18.7 & 0.117125 & 3.07 & \\
27 & 0.117106 & 3.17 & \\
33.8 & 0.117086 & 3.24 & \\
40 & 0.117068 & 3.36 & \\
\hline
\end{tabular}

Table 4 Repetition of the experimental data of the quantification of the residual stresses in Bar 2

\begin{tabular}{|c|c|c|c|}
\hline Angle $\psi\left({ }^{\circ}\right)$ & $\mathrm{d}_{\varphi \psi}(\mathrm{nm})$ & FWHM $\left({ }^{0}\right)$ & Residual stresses $\sigma^{\mathrm{rs} 3}(\mathrm{MPa})$ \\
\hline \multicolumn{4}{|c|}{ Bar 2 (repeated) } \\
\hline 0 & 0.117128 & 3.04 & \\
\hline-18.7 & 0.117099 & 3.19 & \\
\hline-27 & 0.117079 & 3.32 & \\
\hline-33.8 & 0.117055 & 3.48 & \\
\hline-40 & 0.117036 & 3.69 & $-279.5 \pm 18.8$ \\
\hline 18.7 & 0.117122 & 3.07 & \\
\hline 27 & 0.117105 & 3.16 & \\
\hline 33.8 & 0.117084 & 3.26 & \\
\hline 40 & 0.117062 & 3.35 & \\
\hline
\end{tabular}

the separation of the crystallographic planes $\left(d_{\varphi \psi}\right)$ in the nanometer $(\mathrm{nm})$ range, and these values are directly related to the diffraction angles $\left(\theta_{\varphi \psi}\right)$ according to the Bragg diffraction law (Eq. 1). The residual stress values are lower than the elastic limit (400 MPa) of the steel. 


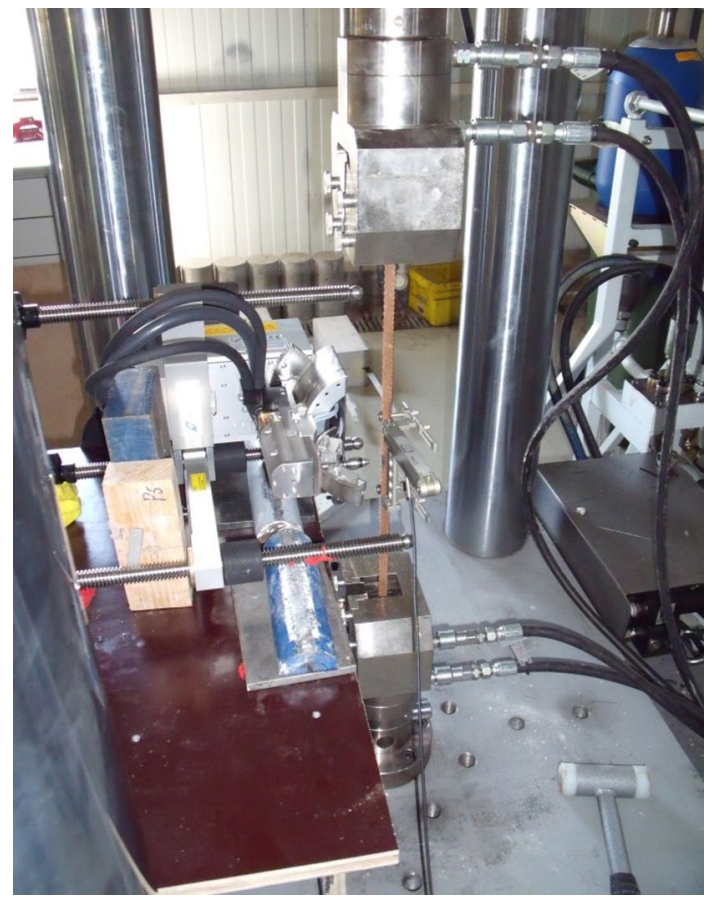

Fig. 12 Positioning of the diffraction equipment before starting the calibration process

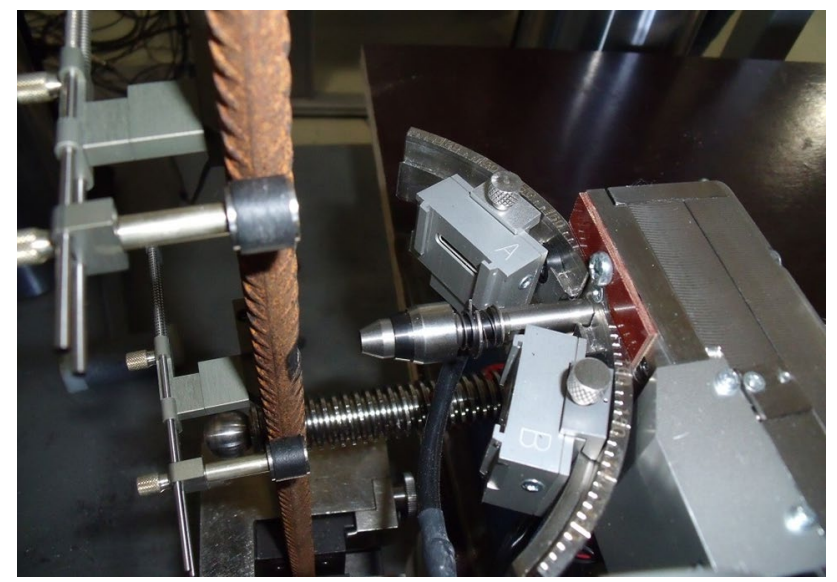

Fig. 13 Arrangement of the diffraction equipment in the calibration process

\subsection{Calibration Tests and Experimental Results}

Subsequently, the bars were subjected to various tensile load states. The tripod of the equipment was supported on a wooden support so that the bars could be mounted in a vertical position; that is, the equipment was rotated $90^{\circ}$ from the location at which the initial residual stresses were measured (Figs. 12 and 13). Before the loading process, the diffraction equipment was tared in situ once more with the bars placed on the machine. In one case, the tare was performed with the bar set by an initial preload in the traction machine (Table 5), while in the other case, the bar was not previously fixed by the machine (Table 7). Tables 5 and 7 show a comparison between the tensile load values applied in the machine $\left(\sigma^{\mathrm{m}}\right)$ and the stresses obtained by diffraction $\left(\sigma^{\mathrm{x}}\right)$. Tables 6 and 8 show a comparison of the values of $\sigma^{\mathrm{m}}$ with the stresses obtained by diffraction by subtracting the values of the residual stresses $\left(\sigma^{\mathrm{rs}}\right)$. The negative sign in Tables 5, 6,7 , and 8 indicates compressive stresses.

Figure 14 shows all the results obtained for both bars (Tables 6 and 8). The experimental values are represented with their absolute error, which is the sum of the error magnitudes $\sigma^{\mathrm{x}}$ and $\sigma^{\text {rs }}$ (Tables 2, 3, 4, 5 and 7). The errors for the magnitude applied in the machine $\left(\sigma^{\mathrm{m}}\right)$ have not been taken into account because their value $(<2 \mathrm{MPa})$ is one order of magnitude lower than the rest of the magnitudes involved in the experimental work.

\section{Discussion and Conclusions}

The steel structural elements in a building are subjected to two types of stress: the residual stresses from the manufacturing and finishing processes and those resulting from the actual loads applied in the structural system. The proposed experimental procedure enables the establishment of a protocol to determine both types of stresses using X-ray diffraction. The methodology is completely nondestructive, which is why it is particularly appropriate for the application to structures in service. The experimental study carried out here involves two research laboratories: the High Technical School of Architecture of the University of the Basque Country UPV/EHU in Spain and the University of Minho (Department of Civil Engineering) in Portugal. The loads applied on the machine by the researchers of
Table 5 Comparison between the stresses applied in the machine $\left(\sigma^{\mathrm{m}}\right)$ with those obtained by diffraction $\left(\sigma^{\mathrm{x}}\right)$ in Bar 1

\begin{tabular}{cllllllll}
\hline$\sigma^{\mathrm{m}}(\mathrm{MPa})$ & Preload $\sigma^{\mathrm{m} 1}$ & $\begin{array}{l}\text { Preload } \sigma^{\mathrm{m} 1} \\
\text { repeated }\end{array}$ & $\sigma^{\mathrm{m} 2}$ & $\sigma^{\mathrm{m} 3}$ & $\sigma^{\mathrm{m} 4}$ & $\sigma^{\mathrm{m} 5}$ & $\sigma^{\mathrm{m} 6}$ & ${\text { Unload } \sigma^{\mathrm{m} 7}}$ \\
& +20 & +20 & +110 & +190 & +225 & +260 & +300 & +20 \\
\hline$\sigma^{\mathrm{x}}(\mathrm{MPa})$ & $\sigma^{\mathrm{x} 1}$ & $\sigma^{\mathrm{x} 1}$ & $\sigma^{\mathrm{x} 2}$ & $\sigma^{\mathrm{x} 3}$ & $\sigma^{\mathrm{x} 4}$ & $\sigma^{\mathrm{x} 5}$ & $\sigma^{\mathrm{x} 6}$ & $\sigma^{\mathrm{x} 7}$ \\
& -261 & -264 & -147 & -74 & -39 & -5 & +27 & -250 \\
& $+/-10$ & $+/-10$ & $+/-17$ & $+/-10$ & $+/-11$ & $+/-9$ & $+/-10$ & $+/-11$ \\
\hline
\end{tabular}


Table 6 Comparison between the stresses applied in the machine $\left(\sigma^{\mathrm{m}}\right)$ and those obtained by diffraction by subtracting the residual stresses in $\operatorname{Bar} 1\left(\sigma^{\mathrm{x}}-\sigma^{\mathrm{rs} 1}\right)$

\begin{tabular}{|c|c|c|c|c|c|c|c|c|}
\hline$\sigma^{\mathrm{m}}(\mathrm{MPa})$ & $\begin{array}{l}\text { Preload } \sigma^{\mathrm{m} 1} \\
+20\end{array}$ & $\begin{array}{l}\text { Preload } \sigma^{\mathrm{m} 1} \text { repeated } \\
+20\end{array}$ & $\begin{array}{l}\sigma^{\mathrm{m} 2} \\
+110\end{array}$ & $\begin{array}{l}\sigma^{\mathrm{m} 3} \\
+190\end{array}$ & $\begin{array}{l}\sigma^{\mathrm{m} 4} \\
+225\end{array}$ & $\begin{array}{l}\sigma^{\mathrm{m} 5} \\
+260\end{array}$ & $\begin{array}{l}\sigma^{\mathrm{m} 6} \\
+300\end{array}$ & $\begin{array}{l}\text { Unload } \sigma^{\mathrm{m} 7} \\
+20\end{array}$ \\
\hline \multirow[t]{2}{*}{$\sigma^{\mathrm{x}}-\sigma^{\mathrm{rs} 1}(\mathrm{MPa})$} & $\sigma^{\mathrm{x} 1}-\sigma^{\mathrm{rs} 1}$ & $\sigma^{\mathrm{x} 1}-\sigma^{\mathrm{rs} 1}$ & $\sigma^{\mathrm{x} 2}-\sigma^{\mathrm{rs} 1}$ & $\sigma^{\mathrm{x} 3}-\sigma^{\mathrm{rs} 1}$ & $\sigma^{\mathrm{x} 4}-\sigma^{\mathrm{rs} 1}$ & $\sigma^{\mathrm{x} 5}-\sigma^{\mathrm{rs} 1}$ & $\sigma^{\mathrm{x} 6}-\sigma^{\mathrm{rs} 1}$ & $\sigma^{\mathrm{x} 7}-\sigma^{\mathrm{rs} 1}$ \\
\hline & +19 & +16 & +133 & +206 & +241 & +275 & +308 & +30 \\
\hline
\end{tabular}

In the last row, only the central values of the experimental measurements are shown

Table 7 Comparison between the stresses applied in the machine $\left(\sigma^{\mathrm{m}}\right)$ and those obtained by diffraction $\left(\sigma^{\mathrm{x}}\right)$ in Bar 2

\begin{tabular}{lllllllll}
\hline$\sigma^{\mathrm{m}}(\mathrm{MPa})$ & $\sigma^{\mathrm{m} 1}$ & $\sigma^{\mathrm{m} 2}$ & $\sigma^{\mathrm{m} 3}$ & $\sigma^{\mathrm{m} 4}$ & $\sigma^{\mathrm{m} 5}$ & $\sigma^{\mathrm{m} 6}$ & $\sigma^{\mathrm{m} 7}$ & $\begin{array}{l}\text { Unload } \sigma^{\mathrm{m} 8} \\
\end{array}$ \\
& 0 & +75 & +150 & +200 & +230 & +265 & +310 & +25 \\
\hline$\sigma^{\mathrm{x}}(\mathrm{MPa})$ & $\sigma^{\mathrm{x} 1}$ & $\sigma^{\mathrm{x} 2}$ & $\sigma^{\mathrm{x} 3}$ & $\sigma^{\mathrm{x} 4}$ & $\sigma^{\mathrm{x} 4}$ & $\sigma^{\mathrm{x} 6}$ & $\sigma^{\mathrm{x} 7}$ & $\sigma^{\mathrm{x} 8}$ \\
& -287 & -222 & -151 & -100 & -73 & -35 & +12 & -270 \\
& $+/-16$ & $+/-12$ & $+/-4$ & $+/-7$ & $+/-5$ & $+/-6$ & $+/-9$ & $+/-8$ \\
\hline
\end{tabular}

Table 8 Comparison between the stresses applied in the machine $\left(\sigma^{\mathrm{m}}\right)$ and those obtained by diffraction by subtracting the residual stresses in $\operatorname{Bar} 2\left(\sigma^{\mathrm{x}}-\sigma^{\mathrm{r} 2}\right)$

\begin{tabular}{lllllllll}
\hline$\sigma^{\mathrm{m}}(\mathrm{MPa})$ & $\sigma^{\mathrm{m} 1}$ & $\sigma^{\mathrm{m} 2}$ & $\sigma^{\mathrm{m} 3}$ & $\sigma^{\mathrm{m} 4}$ & $\sigma^{\mathrm{m} 5}$ & $\sigma^{\mathrm{m} 6}$ & $\sigma^{\mathrm{m} 7}$ & Unload $^{\mathrm{m} 8}$ \\
& 0 & +75 & +150 & +200 & +230 & +265 & +310 & +25 \\
\hline$\sigma^{\mathrm{x}}-\sigma^{\mathrm{rs} 2}(\mathrm{MPa})$ & $\sigma^{\mathrm{x} 1}-\sigma^{\mathrm{rs} 2}$ & $\sigma^{\mathrm{x} 2}-\sigma^{\mathrm{rs} 2}$ & $\sigma^{\mathrm{x} 3}-\sigma^{\mathrm{rs} 2}$ & $\sigma^{\mathrm{x} 4}-\sigma^{\mathrm{rs} 2}$ & $\sigma^{\mathrm{x} 5}-\sigma^{\mathrm{rs} 2}$ & $\sigma^{\mathrm{x} 6}-\sigma^{\mathrm{rs} 2}$ & $\sigma^{\mathrm{x} 7}-\sigma^{\mathrm{rs} 2}$ & $\sigma^{\mathrm{x} 8}-\sigma^{\mathrm{rs} 2}$ \\
& -8 & +58 & +129 & +180 & +207 & +244 & +292 & +10 \\
\hline
\end{tabular}

In the last row, only the central values of the experimental measurements are shown

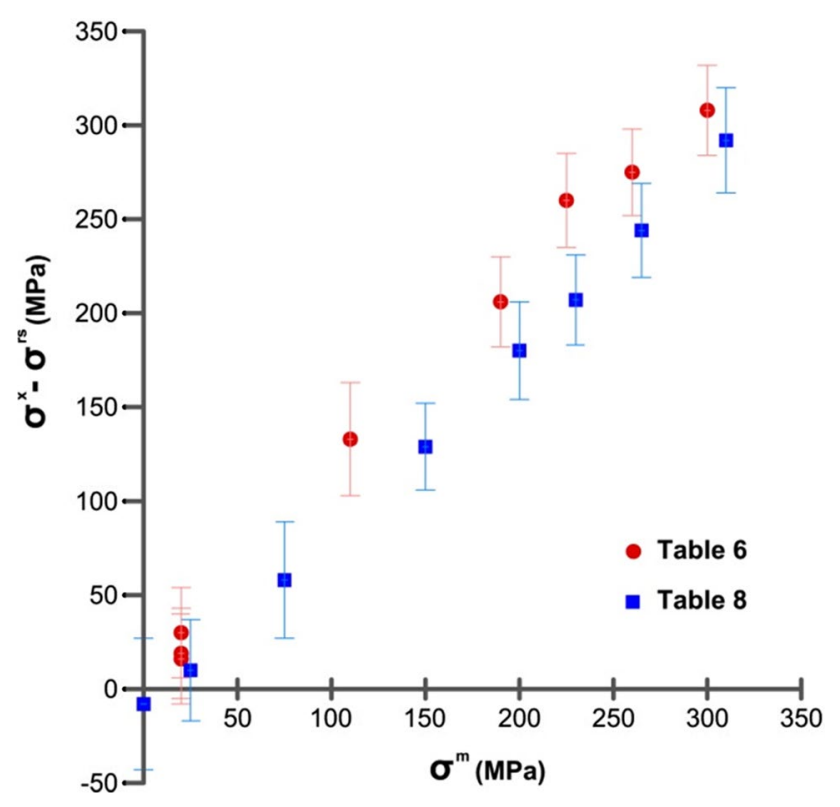

Fig. 14 Correlation between the loads applied in machine $\sigma^{\mathrm{m}}$ and the differences $\sigma^{\mathrm{x}}-\sigma^{\mathrm{rs}}$ in both bars the latter university were unknown by the researchers at the UPV/EHU at the time of estimating the same with the developed procedure.

Once the residual stresses were determined, the stress states applied in the laboratory tensile machine were obtained by diffraction. The results for two bars of the same material have been analyzed in this paper and, in all cases, the values of the loads applied on the machine are within the margin of error for the results obtained by diffraction. The correlation between the experimental results obtained by X-ray diffraction and the loads applied on the machine is excellent. The absolute error in the values obtained by diffraction is related to the full width at half maximum (FWHM) values of the diffraction peaks. This means that the error found does not depend on the stress values present in the material. At the same time, the diffraction peaks are generated during the $5 \mathrm{~s}$ in which the radiation detectors collect the information. A longer exposure time at each position of the " $\psi$ " angle does not improve the quality of the diffracted radiation and does not reduce the value of the FWHM parameter. Consequently, by analyzing the values of the experimental errors, the accuracy of the measureament increases when the stress state is higher, which is important for practical applications (as the objective is to identify critical parts where the 
stresses are large). From $150 \mathrm{MPa}$ onwards, the observed relative error is lower than $10 \%$.

These results obtained corroborate the usefulness of the proposed technique. The natural continuation of this research is the application to real structures in service conditions, which require opening up reinforced concrete structures and clear measurement areas. This is common in the inspection and diagnosis of the condition of reinforced concrete structures and is not understood as an important difficulty in engineering applications.

Acknowledgements The authors thank the National R\&D Plan of the Government of Spain and the University of the Basque Country (UPV/ EHU) for the funding provided within the PES 2012 Program. Special thanks are given to Dr. Luís Ramos from University of Minho for his collaboration in the testing.

Funding Open Access funding provided thanks to the CRUE-CSIC agreement with Springer Nature. National R\&D Plan of the Government of Spain and the University of the Basque Country (UPV/EHU). PES 11/32.

\section{Declarations}

Conflict of interest The authors declare that they have no conflict of interest.

Open Access This article is licensed under a Creative Commons Attribution 4.0 International License, which permits use, sharing, adaptation, distribution and reproduction in any medium or format, as long as you give appropriate credit to the original author(s) and the source, provide a link to the Creative Commons licence, and indicate if changes were made. The images or other third party material in this article are included in the article's Creative Commons licence, unless indicated otherwise in a credit line to the material. If material is not included in the article's Creative Commons licence and your intended use is not permitted by statutory regulation or exceeds the permitted use, you will need to obtain permission directly from the copyright holder. To view a copy of this licence, visit http://creativecommons.org/licenses/by/4.0/.

\section{References}

Artaraz, F., \& Sánchez-Beitia, S. (1991). An unsuitable residual stress state in train springs originated by shot peening. International Journal of Fatigue, 13(2), 165-168. https://doi.org/10. 1016/0142-1123(91)90009-N

ASTM E2860-12. (2012). Standard test method for residual stress measurement by $x$-ray diffraction for bearing steels. ASTM International.

ASTM E1426-14. (2014). Standard test method for determining the $x$-ray elastic constants for use in the measurement of residual stress using $x$-ray diffraction techniques. ASTM International.

ASTM E915-16. (2016). Standard test method for verifying the alignment of $x$-ray diffraction instrumentation for residual stress measurement. ASTM International.

Atienza, J. M., Ruiz-Hervias, J., Caballero, L., \& Elices, M. (2006). Residual stresses and durability in cold drawn eutectoid steel wires. Metals and Materials International, 13, 139-143.
Atienza, J. M., Ruiz-Hervias, J., \& Elices, M. (2012). The role of residual stresses in the performance and durability of prestressing steel wires. Experimental Mechanics, 52, 881-893. https:// doi.org/10.1007/s11340-012-9597-1

Barral, M. (1983). X-ray residual stress measurements on materials with a cristallographic texture (Doctoral dissertation). Univ. Pierre et Madame Curie.

Beck, G., Denis, S., Simon, A., \& Société française de métallurgie. (1989). International conference on residual stresses ICRS 2. Elsevier Applied Science.

Bhadeshia, H. K. D. H. (2002). Material factors. In G. Totten, M. Howes, \& T. Inoue (Eds.), Handbook of residual stress and deformation of steel (pp. 3-10). ASM International.

Castex, L., Lebrun, J. L., Maeder, G., \& Sprauel, J. M. (1981). Publ. Sc. ENSAM No. 22.

Elices, M., Maeder, G., \& Sanchez-Galvez, V. (1983). Effect of surface residual stress on hydrogen embrittlement of prestressing steels. British Corrosion Journal, 18(2), 80-81. https://doi.org/ 10.1179/000705983798273949

FIP-78, International Federation for Prestressing. (1978). Stress corrosion cracking resistance test for prestressing tendons. Technical Report No. 5, FIP.

Fujiwara, H., Abe, T., \& Tanaka, K. (1992). International conference on residual stresses ICRS 3. Elsevier Applied Science.

He, S., Van Bael, A., Li, S. Y., Van Houtte, P., Mei, F., \& Sarban, A. (2003). Residual stress determination in cold drawn steel wire by FEM simulation and X-ray diffraction. Materials Science and Engineering, 346(1-2), 101-107. https://doi.org/10.1016/ S0921-5093(02)00509-9

Hilley, M. E. (Ed.). (1971). Residual stress measurement by x-ray diffraction (2nd ed., pp. 1-119). ASTM SAE Transactions J784a, Society of Automotive Engineers, Inc.

Kröner, E. (1958). Berechnung der elastischen Konstanten des Vielkristalls aus den Konstanten des Einkristalls. Zeitschrift Für Physik, 151, 504-518.

Macherauch, E., Hauk, V., \& Deutsche Gesellschaft für Metallkunde. (1987). International conference on residual stresses ICRS 1. DGM Informations gesellschaft.

McClung, R. C. (2007). A literature survey on the stability and significance of residual stresses during fatigue. Fatigue and Fracture of Engineering Materials and Structures, 30, 173-205. https://doi.org/10.1111/j.1460-2695.2007.01102.x

Noyan, J. C., \& Cohen, J. B. (1987). Residual stress measurement by diffraction and interpretation. Springer. https://doi.org/10. 1007/978-1-4613-9570-6

Reuss, A. (1929). Account of the liquid limit of mixed crystals on the basis of the plasticity condition for single crystal. Zeitschrift Für Angewandte Mathematik Und Mechanik, 9, 49-58.

Ruiz, J., Atienza, J. M., \& Elices, M. (2003). Residual stresses in wires: Influence of wire length. Journal of Materials Engineering and Performance, 12, 480-489. https://doi.org/10.1361/ 105994903770343042

Sánchez-Beitia, S. (1988). Difractometría de Rayos-X: Discusión de los conceptos empleados en la técnica difractométrica de Rayos$\mathrm{X}$ para la deducción de las tensiones residuales y tensiones. Revista Española De Física, 3(1), 42-47.

Sánchez-Beitia, S. (1990). Tensiones residuales y tensiones por difracción de rayos- $X$. Universidad del País Vasco UPV/EHU.

Sánchez-Beitia, S. (2011). Calibration of the x-ray diffraction technique for stress quantification in metallic (steel) structures. Experimental Mechanics, 51(8), 1301-1307. https://doi.org/ $10.1007 / \mathrm{s} 11340-010-9454-\mathrm{Z}$

Sánchez-Beitia, S., \& Barrallo, J. (2014). Quantification of the structural stresses in steel bridges by means of the x-ray diffraction technique: The case of the Bizkaia Bridge (Industrial World 
Heritage Site in Spain). Journal of Testing and Evaluation, 42(4), 20130110. https://doi.org/10.1520/jte20130110

Sprauel, J. M. (1988). Etude par diffraction X des facteurs mécaniques influençant la corrosion sous contraintes d'aciers inoxydables (Doctoral dissertation). Univ. of Paris Sud.

UNE 36068. (2011). Ribbed bars of weldable steel for the reinforcement of concrete.

UNE 36065. (2011). Ribbed bars of weldable steel with special characteristics of ductility for the reinforcement of concrete.

Voigt, W. (1910). Lehrbuch der Kristallphysik. Tenbner.

Willemse, P. F., Naughton, B. P., \& Verbraak, C. A. (1982). X-ray residual stress measurements on cold-drawn steel wire. Materials Science and Engineering, 56, 25-37. https://doi.org/10. 1016/0025-5416(82)90179-3
Withers, P. J., \& Bhadeshia, H. K. D. H. (2001a). Residual stress. Part 1-Measurement techniques. Materials Science and Technology, 17(4), 355-365. https://doi.org/10.1179/0267083011 01509980

Withers, P. J., \& Bhadeshia, H. K. D. H. (2001b). Residual stress. Part 2-Nature and origins. Materials Science and Technology, 17(4), 366-375. https://doi.org/10.1179/026708301101510087

Publisher's Note Springer Nature remains neutral with regard to jurisdictional claims in published maps and institutional affiliations. 